\title{
KREATIVITAS GRUP EGA ROBOT DI BANDUNG JAWA BARAT
}

\author{
Winorman Akbar \\ Program Studi S-1 Etnomusikologi ISI Yogyakarta \\ Email: akbarwinorman2782@gmail.com
}

\begin{abstract}
Abstrak
Kreativitas Ega Robot Ethnic Percussion merupakan perkembangan kesenian tradisi sebagai pijakan untuk berkreativitas, dalam kreativitas yang dilakukan oleh Ega Robot Ethnic Percussion pada lagu Mojang Priangan ini berbeda dengan kelompok-kelompok musik lainnya dikarenakan hasil arransemen Ega Robot Ethnic Percussion merupakan campuran dua elemen musik yang berbeda, yaitu memadukan gamelan salendro dengan instrumen barat sebagai iringan tari jaipongan Mojang Priangan. Metode penilitian yang digunakan untuk membedah krativitas grup Ega Robo Ethnic Percussion menggunakan metode deskripsi analisis dengan pendekatan etnomusikologis. Hasil yang didapat dalam penelitian tersebut yaitu struktur pola lagu Mojang Priangan yang secara keseluruhan merupakan bentuk aransemen dan transformasi dari ragam pola tepak dan iringan dari berbagai kesenian tradisional di Jawa Barat, dengan menambahkan beberapa ragam tepak, perpaduan instrumen barat dan tradisi dengan karya Ega yang akhirnya menimbulkan suatu ciri khas akan grup Ega Robot Ethnic Percussion yang dapat menghasilkan ruang berkreativitas untuk seniman-seniman muda di kota Bandung dalam mengembangkan musik tradisional Sunda.
\end{abstract}

Kata Kunci: Ega Robot Ethnic Percussion, Kreativitas Lagu Mojang Priangan.

\begin{abstract}
Ega Robot Ethnic Percussion creativity is the development of traditional art as a foothold for creativity, in the creativity carried out by Ega Robot Ethnic Percussion on the Mojang Priangan song is different from other music groups because the results of the Ega Robot Ethnic Percussion are a mixture of two different musical elements, namely combining salendro gamelan with western instruments as accompaniment of Mojang Priangan jaipongan dance. The research method used to dissect the creativity of the Ega Robot Ethnic Percussion group uses the description analysis method with an ethnomusicological approach. The results obtained in this study are the structure of the Mojang Priangan song pattern which as a whole is a form of arrangement and transformation of various patterns of pat and accompaniment from various traditional arts in West Java, by adding a number of different types of pat, a blend of western instruments and traditions with Ega's work that ultimately raises a characteristic of the Ega Robot Ethnic Percussion group that can produce a creative space for young artists in the city of Bandung in developing traditional Sundanese music.
\end{abstract}

Keywords: Ega Robot Ethnic Percussion, Kreativitas Lagu Mojang Priangan. 


\section{A. Latar Belakang}

Jaipongan merupakan salah satu bagian rumpun tari kreasi yang mulanya dikembangkan dari kesenian ketuk tilu pada tahun 1916-an, dan tahun 1976. Hal ini ditandai dengan lahirnya jaipongan Suanda Group di Karawang Jawa Barat yang memakai instrumen sederhana, terdiri dari kendang, ketuk, kecrek, goong, rebab dan juru kawih. Berkaca pada kesuksesan ketuk tilu di Karawang, salah satu tokoh jaipongan di Bandung bernama Gugum Gumbira Trisonjaya, kemudian menggali gerak tari dari kesenian ketuk tilu yang dipadukan dengan gerak-gerak pencak silat pada 1970-an, akhirnya menjadi jenis tarian baru yang sampai sekarang dinamakan tari Jaipongan.

Gugum Gumbira membawa tari ketuk tilu ke Bandung dengan tujuan mengembangkan tarian asal Karawang itu menjadi tarian hiburan kreasi. Hal tersebut yang mendasari Gugum Gumbira untuk membuat bentuk tarian dengan pola gerak yang baku/aturan dan sudah terpola. Gerakgerak bukaan, pencugan, nibakeun, dan beberapa gerak mincid dalam ketuk tilu, juga dari beberapa gerakan seni pencak silat, menjadi inspirasi untuk mengembangkan kesenian tersebut yang akhirnya menjadi tari jaipongan.

\section{Perkembangan jaipongan di}

Bandung lebih sukses daripada tempat kelahirannya di Karawang, yang mengalami puncak kepopulerannya pada tahun 1980-an. Pada tahun 2000-an ini tari jaipongan yang menjadi kiblat bagi masyarakat Bandung, baik itu untuk apresiasi, berlatih, melatih, atau menciptakan. Karya pertama Gugum Gumbira masih sangat kental dengan warna ibing ketuk tilu, baik dari segi koreografi maupun iringannya. Karya jaipongan pertama yang mulai dikenal oleh masyarakat adalah tarian Daun Pulus Keser Bojong dan Rendeng Bojong di bawah lingkung seni Jugala pimpinan Gugum Gumbira.

Pada tahun 2000-an di Jawa Barat khususnya di kota Bandung, jaipongan mengalami banyak permbaruan dengan bermunculannya jaipongan gaya baru dalam segi gerak tari dan iringannya. Hal ini ditandai pula dengan lahirnya jaipongan gaya baru yang di antaranya dipopulerkan oleh Ega Robot/Ega Cahyar (grup Ega Robot Ethnic Percussion) dimana salah satu karyanya yang sangat popular yaitu, lagu Mojang Priangan (lagu pop Sunda, yang terkesan feminim) yang diaransemen dan digarap kembali secara vokal maupun instrumental (sekar gending) oleh grup Ega Robot di kota Bandung.

Ega Robot (grup Ega Robot Ethnic Percussion) didirikan oleh Ega Cahyar Mulyana yang lebih dikenal dengan Ega Robot. Ega Robot secara individual dengan grup Ega Robot Ethnic Percussion, 
merupakan satu kesatuan, dengan kata lain, ketika menyebut Ega Robot secara personal maka otomatis terkait langsung dengan grup Ega Robot Ethnic Percussion yang didirikannya. Grup Ega Robot Ethnic Percussion didirikan Ega pada tanggal 21 Desember 2000 di Bandung tepatnya di Cijaura Hilir Kotamadya Bandung.

Beberapa karya musik yang dibawakan oleh grup Ega Robot, terdapat hal yang unik baik dilihat dari aransemen musiknya maupun dari penggunaan instrumennya yang berbeda dengan grup jaipongan klasik pada umumnya yang salah satunya adalah lagu pop Sunda Mojang Priangan yang dipopulerkan oleh penyanyi asal Jawa Barat yaitu Iyar Wiarsih atau lebih dikenal dengan sebutan Mamah Iyar. Garapan musiknya yang dibawakan dalam bentuk format jaipong, tampak berbeda dengan format jaipongan pada umumnya yang sudah terkenal seperti jaipongan oleh Jugala, jaipongan oleh Awan Metro, dan sebagainya.

\section{Lagu Mojang Priangan yang} digarap dan diaransemen kembali oleh Ega, terasa lebih eksploratif, serta lebih fleksibel dalam menafsirkan jargon-jargon musik tradisi karawitan Sunda seperti kesenian sisingaan, kesenian ketuk tilu, dan sebagainya. Perubahan pada gaya-gaya jaipongan versi Ega, Nampak ada pengaruh langsung dari eksperimentasi dari pemain/nayaga yang memiliki latar belakang seniman tradisi dan seniman nyakola/akademisi dan pengolahan media. Hal ini dapat dilihat dari instrumen yang digunakan lebih bervariatif yang tidak hanya memakai Gamelan Salendro seperti garapan musik jaipongan pada umumnya. Namun dalam garapannya, Ega memasukan juga instrumen musik lainnya seperti Biola, dan Latin Percussion. Hal ini didukung juga oleh para personil/pemain dalam grup Ega Robot Ethnic Percussion, yang ratarata sudah terbiasa bermain dalam kesenian tradisi seperti: ketuk tilu, kiliningan, bajidoran, wayang golek, dan sebagainya.

Nama Ega Robot ketika lagu Mojang Priangan diluncurkan dan menjadi jargon pada acara pentas seni pertunjukan yang bertemakan kesenian rakyat, pagelaran jaipongan ini, terlihat adanya gaya eksploratif dengan ditambahkannya drum dan lattin Percussion sebagai instrumen tambahan. Hasilnya tentu saja berbeda dengan musik iringan pop Sunda - seperti yang biasa digunakan untuk mengiringi lagu pop, yaitu band kombo atau electone, namun dalam garapan Ega, lagu Mojang Priangan digarap dan diiringi memakai Gamelan Salendro yang dipadukan dengan instrumen musik Barat seperti gitar electric, drum, biola, bass electric, keyboard, dan lattin percussion.

Penggunaan perpaduan instrumen pengiring dalam lagu Mojang Priangan 
yang dibawakan oleh grup Ega Robot Ethnic Percussion yang tidak lazim dipakai dalam format jaipongan, lagu yang awalnya merupakan jenis lagu pop Sunda, dapat menghasilkan nuansa musikal yang sangat berbeda dan kekinian, terlebih lagi dengan dipadukannya unsur vokal musik Hip Hop (Rap), musik jazz ke dalam garapan lagu Mojang Priangan. Dengan adanya perpaduan baik secara instrumentasi maupun garapan vokal, semakin tampak perbedaan dan rasa musikal yang lebih indah dan dapat menarik antusias anakanak muda untuk menikmatinya. Hal ini terlihat sampai saat ini, masih banyak keluarga yang menyelenggarakan pesta pernikahan, sunatan, dan acara lainnya yang masih banyak menghadirkan kesenian tradisional jaipongan dalam berbagai acara seperti, pernikahan, sunatan, dan lain sebagainya.

Lagu Mojang Priangan untuk mengiringi Tari Jaipongan, memiliki perbedaan dari lagu pop Sunda yang beredar di masyarakat Sunda pada umumnya seperti (Es Lilin, Pati Lalaki, Mawar Bodas, dan sebagainya). Dalam hal ini, lagu-lagu pop Sunda terdahulu diolah oleh Ega Robot sehingga menjadikan musiknya berbeda, mempunyai keunikan baik dari pola permainan laras maupun instrumen yang digunakannya dan digarap dengan mengolah bahan-bahan tradisi (Gamelan Pelog Salendro) yang sudah tersedia yang di dalamnya diolah memakai beragam motif melodi yang berasal dari berbagai jenis genre dan jenis kesenian yang dimiliki masyarakat Sunda. Motif melodi tersebut mengambil dari pola Kiliningan, Ketuk Tilu, dan pola Jaipongan Jugala. Hasil dari pengolahan kreatif tersebut hingga lahir beberapa karya Ega Robot dengan komposer Ega Cahyar / Ega Robot, dengan salah satu karyanya yang populer yaitu lagu Mojang Priangan dipakai sebagai iringan tari jaipongan.

Ketertarikan penulis dalam penelitian ini adalah, lagu Mojang Priangan yang aslinya merupakan lagu pop Sunda, kemudian oleh Ega diaransemen dan digarap dengan menggunakan Gamelan Salendro memakai format Jaipong. Ditambah lagi dengan dibuatnya tarian oleh Pap Gondo (koreografer dari Purwakarta), yang menjadikan lagu Mojang Priangan dikenal masyarakat sebagai lagu jaipongan kreasi yang berbeda dengan jaipongan pada umumnya (klasik).

\section{Karawitan Sunda}

Karawitan Sunda adalah bagian yang tidak terpisahkan dari kehidupan orang Sunda sehari-hari, baik yang sakral maupun yang profan. Begitu eratnya pembaruan anatara satu wilayah kegiatan dengan kegiatan lainnya, sehingga kehadiran kesenian itu sendiri tidak pernah tampil secara mandiri. Atau tidak menjadi 
otonomi seni seperti dikenal dalam kebudayaan Barat, sebagai contoh seni Angklung Buncis, tidak hanya sebagai seni saja, melainkan sebagai upacara agama.

Seni pertunjukan yang berkembang di masyarakat Sunda adalah kesenian untuk para priyai yang berkembang di pendopo kabupaten atau disebut sebagai kalangan menak, dan seni pertunjukan yang berasal dari kalangan rakyat atau seni rakyat. Beberapa jenis kesenian tersebut termasuk ke dalam klasifikikasi kesenian rakyat jelata (golongan somah), beberapa jenis kesenian yang berasal dari kalangan rakyat seperti kesenian Ketuk Tilu, Topeng Banjet, Bajidoran, Tarawangsa, Jaipongan, dan sebagainya. Sedangkan yang termasuk ke dalam kesenian kalangan raja / bangsawan (priyayi) di kota Bandung adalah gamelan Degung klasik, Tembang Cianjuran, Tari Keurseus, dan sebagainya yang semuanya hidup dan berkembang dalam khazanah seni pertunjukan masyarakat Sunda. Hal ini seperti dikatakan oleh Soedarsono dalam Seni Pertunjukan Indonesia di Era Globalisasi menyebutkan, di kalangan istana/kabupaten, berkembang kesenian yang lazim yang disebut seni pertunjukan istana (court performing art), sedangkan di rakyat jelata berkembang seni pertunjukan rakyat (folk performing art).

"Periode 1950-an mungkin akan menunjukan bahwa kesenian rakyat sebagai suatu kategori berlawanan dengan kesenian istana dimulai pada saat itu, sebagai bagian dari satu kampanye mempromosikan bentukbentuk kesenian rakyat sebagai lawan kesenian aristrokratik. Suatu perbedaan jelas antara kesenian rakyat dan kesenian istana dibuat pada akhir 1960-an dan awal 1970-an sebagai reaksi terhadap ketidak jelasan perbedaan yang ada (bagaimanapun interpretasinya) selama awal 1960-an menurunkan nada yang terlalu elit dari bentukbentuk kesenian yang berlainan dengan istana". (Lindsay dalam Bakdi Suimanto, 1991, hlm 44-45)

\section{Kesenian Jaipongan di Kota Bandung}

Jaipongan merupakan salah satu bagian rumpun tari kreasi yang mulanya dikembangkan dari kesenian ketuk tilu pada tahun 1916-an, dan tahun 1976 lahir jaipongan Suanda Group di Karawang Jawa Barat dengan instrumen sederhana yang terdiri dari kendang, ketuk, kecrek, goong, rebab dan juru kawih. Berkaca pada kesuksesan ketuk tilu di Karawang, salah satu tokoh jaipongan di Bandung adalah Gugum Gumbira Trisonjaya, yang merupakan salah satu tokoh pencipta tari jaipongan yang menggali gerak tarian tersebut dari kesenian ketuk tilu dan gerakgerak pencak silat pada 1970-an. Gugum Gumbira membawa tari ketuk tilu ke Bandung dengan tujuan mengembangkan tarian asal Karawang itu menjadi tarian hiburan kreasi. Hal tersebut yang mendasari Gugum Gumbira untuk membuat bentuk 
tarian dengan pola gerak yang baku/aturan dan sudah terpola. Gerak-gerak bukaan, pencugan, nibakeun, dan beberapa gerak mincid dari beberapa kesenian menjadi inspirasi untuk mengembangkan kesenian jaipongan. Perkembangan jaipongan di Bandung lebih sukses daripada tempat kelahirannya di Karawang, yang mengalami puncak kepopulerannya pada tahun 1980-an. Pada tahun 2000-an ini tari jaipongan yang menjadi kiblat bagi masyarakat Bandung, baik itu untuk apresiasi, berlatih, melatih, atau menciptakan. Karya pertama Gugum Gumbira masih sangat kental dengan warna ibing ketuk tilu, baik dari segi koreografi maupun iringannya. Karya jaipongan pertama yang mulai dikenal oleh masyarakat adalah tarian Daun Pulus Keser Bojong dan Rendeng Bojong.

\section{Kota Bandung Sebagai Pusat Kesenian Sunda \\ Bandung merupakan pusat} kebudayaan dan kesenian Sunda, dengan banyaknya jenis kesenian yang ada dan berkembang di Kota bandung. Namun demikian, jenis kesenian rakyat lebih marak perkembangannya dengan masih banyaknya lingkung seni rakyat yang ada di kota Bandung. Hal ini merupakan salah satu proses dimana musik berkembang melalui jalurnya masing-masing, dan juga melalui proses pengolahan kreativitas seniman penggagas. Begitu banyaknya kreasi-kreasi baru yang bermunculan dalam kesenian tradisi, dikarenakan budaya masyarakat Bandung sebagai orang Sunda adalah masyarakat agraris dengan mengutamakan hiburan kerakyatan yang mudah diterima oleh kalangan banyak dan lebih fleksibel.

Seperti yang dinyatakan Mariko Sasaki dalam buku Laras Pada Karawitan Sunda berikut ini:

"Salah satu ciri khas kebudayaan Sunda adalah 'fleksibel' hal ini terlihat jelas dalam hal pembentukan suatu ansamble ataupun dalam penyajiannya, 'fleksibilitas' bisa diartikan juga sebagai ketidak seragaman, agaknya ketidak hadiran sentral kebudayaan bukan semata menimbulkan ketidak seragaman teori serta istilah pada aneka genre kesenian Sunda"

Berdasarkan inilah bisa dikatakan, Bandung merupakan kota yang melahirkan banyak kreasi baru dalam kesenian tradisi termasuk Ega Robot Ethnic Percussion yang menjadikan pusat kreativitas dalam berkesenian di Bandung. Perkembangan teknologi, jelas mempengaruhi bagaimana masyarakat Bandung bertransformasi dari masyarakat tradisional menuju masyarakat yang lebih modern. Hal ini mengubah pandangan hidup masyarakat Bandung unuk berkompetisi dalam hal pekerjaan, dan dalam bidang pendidikan yang sangat mempengaruhi menjadikan Bandung terus 
berkembang. Perkembangan inilah yang mempengaruhi Bandung menjadi kota kraetif, ketika banyak bermunculan komunitas-komunitas menjadikan wadah bagi siapa saja yang ingin menyalurkan kreativitasnya. Bandung juga menjadi trend center bagi kota-kota lain, dari berbagai kuliner, busana, dan musik.

Melihat latar belakang kota Bandung dan masyarakatnya heterogen, sedikit banyaknya menyebabkan adanya pengaruh budaya luar yang mempengaruhi masyarakat Bandung baik dari sisi budaya, kesenian/musik, maupun mode. Dengan berbagai pola berfikir yang terus berkembang hingga saat ini, manusia tidak berhenti untuk berkreativitas dengan terus mencari sesuatu hal yang baru. Hal ini memberi kesempatan bagi senimanseniman muda, dimana Bandung sebagai tempat berkumpulnya musik-musik indie akan memberi peluang kepada senimanseniman muda yang berkreativitas dalam seni tradisional memberi warna baru dari tradisional dan memberi kebutuhan pasar. Ketika sudah adanya kejenuhan masyarakat Bandung akan musik-musik indie yang bertebaran, di sini lah peran seniman muda dalam musik tradisional memberi warna baru yang dapat diteriman oleh kalangan anak muda.

\section{B. Metode Penelitian}

Penelitian ini menggunakan jenis kualitatif narasi melalui upaya mengkaji antara instrumen dan ragam gaya musikal di dalam lagu Mojang Priangan serta menganlisis bentuk musiknya, dan bagaimana dampak kreativitas dari grup Ega Robot Ethnic Percussion terhadap perkembangan jaipongan pada umumnya yang beredar di masyarakat kota Bandung.

Cresswel (2011) menjelaskan bahwa narasi merupakan salah satu metode penelitian kualitatif yang fokus terhadap deskripsi fenomena ataupun seseorang. Sehingga teknik pengumpulan data dilakukan dengan observasi, wawancara dan studi pustaka. Sedangkan pada tahapan analisis data pengelompokan dan reduksi menjadi sebuah langkah sesuai dengan uraian Moist

\section{Hasil dan Pembahasan \\ Biografi}

Ega Robot Ethnic Percussion didirikan oleh Ega Cahyar Mulyana pada tanggal 21 Desember 2000 di Kota Bandung. Grup ini merupakan ruang Ega berkreatifitas pada bidang musik, melalui grup ini jati diri Ega sebagai seorang seniman seni pertunjukan berbasis budaya lokal Jawa Barat terbentuk.

Ega lahir dan dibesarkan di kalangan seniman tradisi dimana ayahnya sebagai seniman sisingaan di daerah Subang yang terkenal dengan nama atau 
julukan Bapa Robot. Nama "Robot" diambil dari nama populer sang ayah yaitu Pak Robot atau lebih dikenal dengan julukan "Si Robot". Pak Robot merupakan maestro kendang Sunda sekaligus seniman sisingaan asal Subang Jawa Barat. Alasan masyarakat memanggil ayah Ega dengan sebutan "Robot" karena karakteristik dalam permainan kendangnya boborobotan atau kuat dan kencang, terlebih pada saat itu masih sangat minim teknologi sound system pada sebuah acara pertunjukan, maka orang memanggilnya dengan sebutan "Si Robot", karena suara dari pukulan kendangnya keras/ngaborobot yang tidak tergantung pada bantuan sound system.

Ayah Ega adalah seorang yang memprakarsai kesenian Sisingaan di daerah Subang Jawa Barat dan beliau adalah penyusun dan penggubah ragam-ragam tepak kendang pada Sisingaan dan menyusun koreografi ibing sisingaan. Macam ragam ibing tersebut diantaranya adalah: Ewal, Solor, dan Gondang.

Sejak umur 5 tahun Ega sudah menjadi pengendang cilik dan mahir bermain kendang, pada saat itu sang ayah sering membawa Ega untuk ikut manggung dari panggung satu ke panggung yang lain. Pada tahun 1980-an tepatnya saat sedang mengenyam pendidikan sekolah menengah pertama Ega sudah mahir mengiringi kesenian ketuk tiluan, jaipongan, dan sisingaan. Pengalaman dasar musikal tradisi lebih diperkental melalui pendidikan formal. Pada tahun 1991 awal mula Ega hijrah ke kota Bandung untuk mengenyam pendidikan ke Sekolah Menengah Karawitan Indonesia (SMKI) di Kota Bandung.

Semasa menempuh pendidikan di SMKI, Ega bergabung dengan grup Gentra Madya pimpinan salah seorang maestro karawitan Sunda yaitu almarhum Nano Suratno hingga berlanjut dan lulus dari fakultas seni pertunjukan Universitas Pendidikan Indonesia (UPI) Bandung tahun 1995. Selain bergabung dengan Gentra Madya, selama menempuh pendidikan di Kota Bandung Ega dan kawan-kawannya membentuk sebuah grup upacara adat yaitu grup Santika Laras dan bergabung dengan grup musik DKSB pimpinan Harry Roesli di Bandung.

Tahun 1995 hingga tahun 2000-an, Ega banyak berperan sebagai arranger di grup Gentra Madya dan mengaransemen lagu-lagu kacapi kawih, degung, dan Jaipongan karya-karya Nano S. Tepat pada tahun 2000, Ega mulai merintis grup rampak kendang yang ia beri nama Ega Robot Ethnic Percussion.

Ega Robot Ethnic Percussion merupakan grup yang konsisten pada jalur karawitan Sunda. Awal terbentuknya grup ini, karena ada kekhawatiran dan keprihatinan Ega, akan perkembangan musik tradisional Sunda. Kekhawatiran Ega 
ini diakibatkan karena masuknya arus informasi budaya dari manca negara yang turut menyurutkan minat generasi muda terhadap seni tradisi/karawitan Sunda. Tahun 2000 Ega Robot Ethnic Percussion mengusung konsep musik lokal untuk menjadikan musik yang universal yang dapat membuat warna baru dalam komposisi musik tradisi karawitan Sunda.

Nama Ega Robot Ethnic Percussion tersebut diilhami oleh penyebutan instrumen pukul percussion atau perkusi. Hal ini diperkuat oleh Machfauzia dalam bukunya Kamus Musik dan Istilahnya menyebutkan bahwa alat musik perkusi bertanggung jawab dalam menentukan ritme dan ketukan dalam sebuah komposisi musik. Perkusi adalah jenis alat yang dimainkan dengan cara dipukul, dikocok, atau digesek. Keberangkatannya berawal dari instrumen kendang yang kurang diminati oleh kalangan muda dan dianggap sebelah mata, tetapi bagi Ega alat musik kendang bisa memberi warna terhadap musik-musik populer saat ini dengan inovasi-inovasi baru bagi musik tradisional dalam mengembangkan nilai seni budaya Sunda pada umumnya.

\section{Ega Robot Ethnic Percussion} sebagai sebuah komunitas atau grup musik, tentu mempunyai tujuan dan ranah terkumpulnya seniman-seniman muda berpotensi. Visi Ega Robot Ethnic
Percussion adalah memberikan wahana dan identitas baru bagi musik tradisional Indonesia, khususnya musik tradisional Sunda dan menjadikan musik tradisional Sunda sebagai identitas budaya Indonesia. Misi Ega Robot Ethnic Percussion adalah mengkomunikasikan musik tradisional secara luas, serta membawa generasi muda agar lebih peduli dan menghargai akar seni radisi budaya Sunda. Oleh sebab itu, Ega Robot Ethnic Percussion terus berupaya agar musik tradisional Sunda, dapat diperhitungkan di dunia Global dan dapat disejajarkan dengan genre musik lainnya yang ada di dunia.

Pada tahun 2000, Ega Robot Ethnic Percussion mulai membuat rekaman untuk album jaipongan dan mempunyai perubahan gaya musikalnya yang lebih eksploraif, inovatif serta lebih fleksibel, namun tidak menghilangkan ciri ketradisiannya. Selain menggunakan seperangkat gamelan salendro dalam garapannya, Ega Robot Ethnic Percussion mencoba eksperimen dengan menggunakan intrumen barat dan arumba. Ega robot akhirnya mengeluarkan album pertamanya yang Ega buat adalah Jaipong Inovative yang diresmikan pada tahun 2004 yang kemudian dibeli oleh produser asal negara Jepang yaitu Tanaka Shan dengan label GNP (Gema Nada Pertiwi) dengan jumlah tujuh lagu dalam satu album. Beberapa lagu dalam album pertamanya yaitu Jaipong 
Inovative adalah: Ampun Teuing, Gandrung, Mojang Priangan, Kaca-Kaca, Salam Tepang, Tablo, dan Senggot Kaleran.

\section{Penyajian Musik Grup Ega Robot Ethnic Percussion}

Untuk mengalanis teks dalam penelitian ini, diambil sampel lagu Mojang Priangan yang telah membawa grup Ega Robot Ethnic Percussion mencapai puncak kepopulerannya, dimana masyarakat mengenal Ega Robot/grup Ega Robot Ethnic Percussion tidak hanya sebagai seniman tradisi namun semakin dikenal sebagai seniman yang inovatif dan kreatif dalam karya-karyanya. Dalam membahas masalah ini, dapat dikaji dari dua aspek yaitu, aspek Musikal dan aspek non musikal.

Karawitan Sunda secara pertunjukannya, dibagi menjadi tiga jenis kelompok besar yaitu, karawitan sekar/vokal, karawitan gending/instrumenal, dan karawitan sekar gending/perpaduan antara vokal dan instrumenal. Lagu pada Mojang Priangan termasuk ke dalam jenis sekar gending, karena di dalamnya ada unsur lagu/melodi dan gending menjadi satu kesatuan. Bila dilihat dari bentuk dan motif tabuhan yang menonjol dalam gending tersebut, pada dasarnya berasal dari bentuk-bentuk tabuhan musik tradisi antara lain Ketuk Tilu, Kiliningan, dan Jaipongan. Hal tersebut dapat terlihat dari pola iringan dasar dengan menggunakan struktur balungan karawitan Sunda baik secara melodi iringan maupun irama pada iringan.

Lagu Mojang Priangan sebelumnya adalah termasuk ke dalam lagu pop Sunda yang diciptakan oleh Iyar Wiarsih yang kemudian diarransmen ulang pada tahun 2002-an oleh Ega Cahyar pimpinan grup Ega Robot Ethnic Percussion, menjadi versi kreasi baru. Dasar kreativitas Mojang Priangan karya Ega Robot mengambil pola lagu dan gending jaipongan yang sudah populer sebelumnya, seperti mengambil motif iringan seperti mincid, tepak sisingaan, dan sebagainya yang menjadi pijakan dalam berkreativitas.

Pada hal ini dalam mentranskripsi lagu Mojang Priangan, menggunakan notasi daminatila dan menggunakan laras salendro. Titi laras (notasi) daminatila, diciptakan oleh Raden Machyar Angga Koesoemadinata sekitar tahun 1924. Titi laras ini menggunakan notasi angka mulai dari angka satu sampai dengan angka lima.

Susunan lagu Mojang Priangan cukup sederhana, karena tidak mengacu kepada aturan karawitan yang baku terutama aturan bentuk komposisi Jaipongan klasik. Susunan pola lagu Mojang Priangan mengikuti susunan lagu aslinya, yang mebedakan adalah versi 
terdahulu yaitu pop kemudian diarransmen menjadi versi Jaipong kreasi karena dilihat dari instrumen musik yang digunakan pada lagu ini yaitu seperangkat gamelan, dan instrumen non gamelan, maka susunanya tidak terlalu rumit. Hasil wawancara dengan Ega pada bulan November 2019, dalam lagu Mojang Priangan ada 4 bagian yaitu (1) intro/bubuka, (2) iringan lagu, (3) interlude (4) ending.

Bagian pertama ini adalah struktur gending yang digunakan pada Bubuka/intro lagu Mojang Priangan dengan laras Salendro. Laras yang dugunakan dalam lagu Mojang Priangan, menggunakan laras Salendro surupan 2 = Tugu pada gamelan untuk iringannya, dan Laras Madenda $4=\mathrm{P}$ untuk lagunya. Gamelan yang dipakai adalah gamelan selap/multilaras (laras salendro, pelog, madenda, mataraman), namun untuk mengiringi lagu Mojang Priangan, laras yang dipakai adalah laras salendro. Untuk penulisan notasi, menggunakan notasi daminatila yaitu:

Pada bagian intro Mojang Priangan melodi mengambil dasar nada dari pola tabuhan Bonang dan dimana pada pola melodi di atas, mengambil dari kenongan 1 (da) dan goongannya 4 (ti) pada lagu gendu dalam pembawaan melodinya yang setelah diolah oleh Ega sehingga menghasilkan nada yang berbeda. Dengan kalimat Tanya dan dijelaskan lagi dengan kalimat jawab.
Contoh pada kalimat tanya : Contoh pada kalimat jawab :

$$
\| \overline{\overline{43}} \overline{\overline{21}} \overline{51} \overline{\overline{43}} \overline{\overline{21}} \overline{\overline{51}}
$$

$$
\overline{43} \quad \overline{21} \quad \overline{51} \quad \overline{23} \quad \overline{(4)}
$$

Bagian pertama ini menggunakan pola Iringan dan tepak kendang khusus dalam lagu Mojang Priangan diciptakan oleh Ega dari hasil kreatifitasnya sendiri, kemudian menjadikannya terlihat berbeda dan memberikan warna pada lagu tersebut. Iringan dan tepak khusus dalam lagu Mojang Priangan yang menonjol pada bagian intro lagu, terdapat motif permainan drum pada birama dua dan birama empat, kemudian dilanjutkan seperti motif pukulan djimbe pada birama 5 namun dalam Jaipongan motif ini disebut motif tepak diropel.

Notasi Kendang dalam karawitan Sunda memiliki berbagai versi, hal ini dikarenakan mengikuti kebiasaan para seniman dalam menggunakannya. Penotasian Kendang sampai saat ini belum ada keseragaman terutama pada notasi Kendang Jaipongan. Kebiasan para seniman dan pengrawit Kendang mengandalkan hafalan pola-pola tepak Kendang sesuai dengan tafsir dan selera masing-masing, sehingga hal ini 
mempengaruhi keberagaman notasi

Kendang dan perkembangannya.

\section{Dampak Kreativitas Grup Ega Robot Ethnic Percussion}

Dampak dalam kehidupan manusia, merupakan suatu hal yang harus dilalui dan dirasakan sebagai persoalan yang lumrah dan wajar. Hal ini disebabkan karena manusia bergaul dan dipengaruhi oleh suatu proses perkembangan. Fenomena perubahan ini menjadi positif sifatnya ketika hal tersebut dianggap memenuhi kebutuhan dan mempunyai nilai manfaat oleh suatu masyarakat tertentu, dan menjadi negatif ketika justru dapat merusak tatanan nilai-nilai yang ada dalam masyarakat. Seperti karakter indiferen, yang mempunyai arti tidak terkotak-kotak antara aspek satu dengan aspek lainnya, melainkan saling berkaitan.

Kesenian memiliki kecenderungan untuk berubah atau bertambah statusnya. Demikian halnya dengan musik tradisi yang karena perkembangan dan pergaulannya, kemudian bias bertambah statusnya. Dalam seni tradisi khususnya, faktor seniman sebagai seorang pemeran dalam sistem komunikasi inter dan intera pada awalnya hanya berkutat pada persoalan keindahan, keragaman proses kreatif keseniannya. Sesuai perkembangannya, kini menjadi persoalan kebutuhan hidup ekonomi, pertunjukan, pengemasan bahkan sampai pada persoalan pasar atau komersial. Hal ini bukan sebuah kejutan sesaat, namun sebuah proses alami yang akan dilaluinya dari hari ke hari oleh para seniman tersebut. Pandangan terhadap fungsional musik yang terus berkembang itu, didukung pula oleh kemajuankemajuan dalam bidang ilmu pengetahuan yang antara lain menghasilkan alat-alat perhubungan seperti radio dan televisi.

Ega Robot Ethnic Percussion sebagai suatu bentuk musik genre baru dalam dunia musik tradisi di Jawa Barat, telah menapaki perjalanannya melalui berbagai proses, dan mengembangkan musik tradisi dengan garapan kreasi baru tidak lepas dari waditra Sunda sebagai media kreativitasnya. Dalam kreativitasnya, Ega Robot Ethnic Percussion pada lagu Mojang Priangan mempunyai pengaruh terhadap kesenian Sunda dimana hasil karyanya banyak dinikmati oleh kalangan masyarakat Sunda yang memiliki sanggar-sanggar seni tradisional tari, karya-karya pada jaipongan Mojang Priangan sering digunakan sebagai iringan tari, dan lagu Mojang Priangan karya Ega Robot ini pernah dijadikan lagu wajib dalam pasanggiri tari Jaipongan seProvinsi Jawa Barat tahun 2015.

Hal ini pengaruh Ega Robot Ethnic Percussion terhadap kesenian Sunda tidak hanya dibidang seni jaipongan, tetapi dibidang karawitan sangat berpengaruh 
besar dari kreativitas dan pemikirannya mengembangkan kesenian Sunda ke modern. Hal ini dilakukan untuk meningkatkan minat generasi muda terhadap karawitan Sunda, tujuan lain adalah agar karawitan Sunda lebih menarik minat masyarakat luas dan memiliki nilai jual serta nilai tambahan bagi seniman. Ega Robot Ethnic Percussion sendiri berupaya membawa karawitan Sunda menjadi musik dunia yang professional. Adapun sebagai tujuan secara hakikinya untuk mempersatukan bangsa dengan berkesenian.

Kehadiran komposer-komposer masa kini memberikan pencerahan baru bagi karawitan Sunda. Dengan genre (aliran) perkembangan masing-masing kreativitas, berhasil melestarikan mengembangkan ciri khas dari suatu benang kebudayaan lokal serta menjadikan karawitan Sunda eksis di tatar Lokal, Nasional, bahkan Internasional. Kreativitas Ega Robot di bidang musik yang sangat berbeda dengan yang lainnya memiliki keunikan secara aransemen, musikalitas, karya yang inovatif dan eskploratif termasuk dengan cara menyajikannya sangat berbeda dan di dukung dengan para musisi-musisi yang sangat handal dan memiliki bakat kesenian di bidang karawitan.

Kreativitas merupakan kemampuan seseorang untuk melahirkan sesuatu yang baru, baik berupa gagasan maupun karya nyata, yang relatif berbeda dengan yang telah ada sebelumnya. Proses pengaruh Ega Robot Ehnic Percussion terhadap masyarakat Bandung dari generasi ke generasi berikutnya, menjadi pengaruh sedikit demi sedikit. Kemudian hasil perubahannya baru akan tampak jelas setelah beberapa tahun kemudian peristiwa pengaruh seperti ini bersifat alami, tidak dibuat atau dipaksa. Hasil dari pengaruhnya dapat diterima oleh masyarakat pendukungnya. Kemunculan Ega Robot dengan gamelan Sunda sebagai media utamanya dianggap mempunyai pengaruh kepada seniman-seniman jaipongan di Bandung pengaruh baik secara instrumen dan pembawaan komposisinya serta lebih dinamis dan mempunyai karakter selera anak-anak muda.

Keberhasilan Ega Robot tidak dapat dipisahkan dari masyarakat. Kepuasan masyarakat selalu menjadi pemikiran Ega Robot untuk bergerak lebih baik lagi. Oleh karena itu membaca situasi, trend/selera, dan kondisi lapangan selalu dilakukan oleh Ega Robot dalam proses membuat karya musik. Hal ini dilakukan agar musik yang disampaikan, mendapatkan respon dari masyarakat dan menimbulkan interaksi antara keduanya dan mempunyai nilai yang lebih.

Pengaruh Ega Robot di tengah masyarakat dengan kreativitasnya, 
mempunyai pengaruh sebagai arah kreativitas dalam musik kreasi Sunda, selain Ega Robot sebagai arah seniman muda dalam kreativitas. Ega robot memberi peluang kepada generasi selanjutnya untuk belajar dan menghasilkan karya-karya baru. Ega Robot menyadari perkembangan dan kebesaran musik Sunda sangat tergantung pada generasi muda pendukung untuk berkarya pada musik tradisional Sunda. Hal ini dilakukan oleh Ega Robot sebagai salah satu cara untuk mencari semangat anak muda untuk peduli terhadap musik tradisional Sunda, dan melahirkan senimanseniman muda di Bandung.

\section{Simpulan}

Berdasarkan hasil pengamatan baik secara langsung kepada masyarakat seni (seniman), tradisi atau masyarakat umum pada dasarnya sebagian besar masyarakat Sunda mengenal Ega Robot, namun masalah dengan adanya pro dan kontra itu menjadi hal yang wajar dan menjadi acuan untuk lebih baik lagi dalam penggarapan setiap karya-karya Ega Robot dari sebelumnya. Perkembangan kesenian tradisional Sunda dari tahun ke tahun mengalami perubahan yang sangat pesat bahkan dengan lahirnya para musisi-musisi muda dan seniman muda seperti Ega Cahyar Mulyana berlatar belakang pendidikan seni karawitan mampu membuat terobosan-terobosan baru dalam menciptakan karya musik dengan menggabungkan beberapa jenis warna musik. Kepiawayan dalam memainkan beberapa jenis musik dan perjalanan dalam berkesenian yang sangat panjang sehingga lebih mudah merancang duatu tatanan musik untuk berkreasi lebih luas, dapat dibuktikan dari hasil karya-karyanya yag sudah banyak dimunculkan dan dapat diterima di dalam negeri maupun luar negeri karena kesinergiannya dalam berkarya.

Bermunculannya kelompokkelompok musik, terinspirasi oleh Ega Robot, saat ini yang hampir banyak grup musik yang menyerupai Ega Robot, baik dalam berkreativitas, instrumen hingga bentuk penyajiannya. Berkembangnya grup-grup musik etnis di Bandung yang mempunyai pengaruh dari Ega Robot seperti: Astinapura, Rayapro, Jimbot, Saratuspersen, Sekar Balebat, Karsiwa, dan Jaipong Disco.

\section{E. Daftar Pustaka}

Afriyanto, Sudendi. 2002. Kreativitas dan Motivasi untuk Melakukan Proses Kreatif. (Makalah yang disajikan pada forum Diskusi Himpunan Mahasiswa Jurusan Karawitan Sekolah Tinggi Seni Indonseia, Bandung, 23 Mei 2002).

Caturwati, Endang. 2008. Tradisi Sebagai Tumpuan Kreativitas Seni. Bandung: Sunan Ambu Press. 
Daily Of Luthier, https://asiaprosound.com/washburnpxm-20-frf, diakses tanggal. 3 Desember 2019

Djohan, 2009. Psikologi Musik. Yogyakarta: Buku Baik.

Ekadjati, Edi S. 1995. Kebudayaan Sunda: Suatu Pendekatan Sejarah. Jakarta: Pustaka Jaya.

Hermawan, Deni. 2002. Tangga Nada Musik Sunda: Antara kenyataan Teoritis dan Praktis. Dalam Etnomusikologi: Beberapa Permasalahan dalam Musik Sunda. Bandung: STSI Press.

Iswantara, Nur. 2017. Kreativitas Sejarah, Teori \& Perkembangan, Yogyakarta: Gigih Pustaka Mandiri.

Koesoemadinata, R. Machyar Angga. 1969. Ilmu Seni Raras. Djakarta: Pradnja Paramita.

Kurniawan, Wawan. 2014. "Kreativitas Sambasunda di Bandung: Studi Kasus Lagu Bajidor Kahot”, Skripsi untuk mencapai derajat sarjana S-1 pada Program Studi Etnomusikologi, Fakultas Seni Pertunjukan, Institut Seni Indonesia Yogyakarta, Yogyakarta,

Lindsay, Jenifer. 1991. Klasik, Kitch, Kontemporer: Sebuah Studi Tentang Seni Pertunjukan Jawa. Terj. Nin Bakdi Sumanto. Yogyakarta: Gadjah Mada University Press.

Merriam, Alan P. 1964. The Antrophology of Music. Terj. Triyono Bramantyo, Nirthwestern: University Press.
Moeloeng, J Lexy. 2017. Metode Penelitian Kualitatif. Bandung: PT. Remaja Rosdakarya.

Nakagawa, Shin. 2000. Musik dan Kosmos: Sebuah Pengantar Etnomusikologi, Jakarta: Yayasan Obor Indonesia.

Natapradja, Iwan. 2003. Sekar Gending. Bandung: PT. Karya Cipta Lestari.

Rusman, Yus. 2008. Menjadikan Tradisi Sebagai Tumpuan Kreativitas. Bandung: Sunan Ambu Press.

Sasaki, Mariko. 2007. Laras Pada Karawitan Sunda. Bandung: Pusat Penelitian dan Pengembangan Pendidikan Seni Tradisional, Universitas Pendidikan Indonesia (P4ST UPI).

Saepudin, Asep. 2013. Garap Tepak Kendang Jaipongan dalam Karawitan Sunda. Yogyakarta: BP ISI Yogyakarta.

Senen, I Wayan. 2002. Wayan Bratha Pembaharu Gamelan Kebyar Bali. Yogyakarta: Terawang Press.

Soedarsono, R.M. 2002. Seni Pertunjukan Indonesia di Era Globalisasi, Yogyakarta: Gadjah Mada University Press.

2003. Seni Pertunjukan Dari Prespektif Politik, Sosial, Budaya, dan Ekonomi. Yogyakarta: Gadjah Mada University Press.

Soeharto, M. 1992. Kamus Musik. Jakarta: PT. Gramedia Widiasarana Indonesia.

Soepandi, Atik. 1988. Kamus Istilah Karawitan Sunda, Bandung: Pustaka Buana. dan Atmadibrata, Enoch. 1977. Khazanah Kesenian Daerah Jawa Barat. Bandung: Pelita Masa. 
Upandi, Pandi. 2009. Metode Pembelajaran Kiliningan Kawih dan Gending Pirigannya. Bandung: STSI Press.

Warnika, Engkos dan Suratno, Nano. 1983. Pengetahuan Karawitan Sunda. Jakarta: Departemen Pendidikan dan Kebudayaan. 